\author{
Г. Н. Швецова-Водка, 3. В. Романуха \\ Ровенский государственный гуманитарный университет, \\ Ровенская областная универсальная научная библиотека
}

\title{
Справочно-библиографическое обслуживание: терминологический аспект
}

Проанализирована современная терминология справочно-библиографического обслуживания, выявлены дискуссионные моменты, отражены некоторые формулировки терминов и определений основных понятий. Рассмотрены понятия «электронная справка», «виртуальная справка», «виртуальная справочная служба». Предложена многоаспектная классификация видов справок и консультаций.

Ключевые слова: справочно-библиографическое обслуживание, справка, консультация, виртуальная справочная служба, виды и типы справок.

UDC 025.5

Galina Shvetsova-Vodka, Zoya Romanukha

Rivne state humanitarian university,

Rivne regional universal scientific library, Rivne, Ukraine

\section{Reference and bibliographic service: Terminology}

The terminology of reference and bibliographic service is analyzed; disputable aspects are revealed; several terms and definitions are formulated. The terms "electronic reference", "virtual reference", "virtual reference service" are examined. A multiaspect classification for references and consultations is proposed.

Keywords: reference and bibliographic service, virtual reference service, reference types.

Справочно-библиографическое обслуживание (СБО) относится к наиболее изученным и хорошо известным практикам направлениям деятельности любой библиотеки. Терминология, методика и технология СБО освещены во многих работах, особенно тщательно исследованы И. Г. Моргенштерном, Е. Д. Жабко, М. Ю. Нещерет и другими. Недавняя фундаментальная публикация на эту тему - монография Т. В. Добко [10]. 
СБО рассмотрено практически во всех учебниках и учебных пособиях, посвящённых библиографоведению, в том числе - в недавно вышедшем учебно-практическом пособии Н. В. Абросимовой «Библиографическая деятельность библиотеки», которое адресовано «работникам библиотек, не имеющим специального образования», и «студентам библиотечноинформационных факультетов вузов и колледжей» [1].

Пособие вышло в серии «Азбука библиотечной профессии». Это говорит о том, что в нём отражены устоявшиеся знания, азы профессии, не вызывающие сомнений и дискуссий. Вероятно, так и нужно «подавать» знания начинающим. Однако не получится ли так, что сомнительные терминологические решения будут восприниматься как не подлежащие пересмотру, а теоретические знания о СБО - ограниченными опытом предыдущих лет, не отражающими новых фактов и явлений.

Рассмотрим критически современную терминологию СБО, выявим дискуссионные моменты и предложим решения.

Начнём с определения. Что такое СБО? Действующий в настоящее время ГОСТ 7.0-99 «Информационно-библиотечная деятельность, библиография. Термины и определения» предлагает следующее определение: «Обслуживание в соответствии с запросами потребителей информации, связанное с предоставлением справок и других библиографических услуг» [7. С. 17]. Термин $С Б О$ помещён в разделе «Информационное обслуживание», поэтому следует предположить, что СБО рассматривается как вид информационного обслуживания, однако в определении это не отражено.

Никак не связано понятие СБО и с термином библиографическое обслуживание, который трактуется как «Обеспечение потребителей библиографической информацией» [Там же]. Разве не было бы логичным определить библиографическое обслуживание как «информационное обслуживание, обеспечивающее потребителей библиографической информацией», а СБО - как «библиографическое обслуживание...»? К дальнейшему тексту определения СБО также есть замечания, которые ещё в 2002 г. высказали И. Г. Моргенштерн и Г. А. Губанова: следовало уточнить характер запросов (разовые) и «других библиографических услуг» [8].

Правильнее было бы вернуться к определению СБО из предыдущего ГОСТа 7.0-84 «Библиографическая деятельность. Основные термины и определения»: «Библиографическое обслуживание в соответствии с разовыми запросами потребителей информации» [6. С. 17]. Следовало бы только уточнить, что такое «разовый информационный запрос»: запрос на информацию, связанный с эпизодической информационной потребностью, требующей оперативного удовлетворения. В определении СБО не нужно 
перечислять, из каких процессов оно состоит, какую информацию предоставляет и в какой форме (справки или «другие услуги»). Всё перечисленное может быть дано в развёрнутой характеристике СБО, но не в определении.

Процессы СБО (по И. Г. Моргенштерну: приём разовых запросов, справочно-библиографический поиск, выдача информации пользователям [15. С. 8]) называют также этапами выполнения справки. Количество этих этапов и их названия у разных авторов различаются. О. П. Коршунов считал, что СБО «состоит в приёме запроса потребителя на информацию и выдаче ему ответа на запрос» [14. С. 169]. Н. Н. Щерба назвал шесть этапов СБО: приём запроса; установление круга источников, необходимых для оптимального удовлетворения запроса; поиск информации; оформление справки; регистрация справки в журнале учёта справок и консультаций и выдача (отправление) её абоненту [2. С. 169].

Г. Н. Диомидова в общей программе (алгоритме) поиска выделяет четыре этапа: «информационную подготовку поиска» - приём, регистрацию и анализ запроса; «моделирование источников поиска» (определение предполагаемых источников); «выбор оптимального пути поиска» (отбор предполагаемых источников); «реализацию поисковой программы (получение информации, отвечающей требованиям запроса)», оформление справки [9. C. 225, 226].

«Путь справки», по мнению И. Г. Моргенштерна, также состоит из четырёх этапов. Они называются по-другому, есть и некоторые отличия в содержании каждого этапа: 1. Приём и анализ запросов. 2. Подбор и анализ источников. 3. Поиск в источниках. 4. Оформление, выдача и регистрация справки [15. С. 24; 17. С. 450-456].

Предлагаемая Э. Г. Разумовой технология обслуживания удалённых пользователей состоит из шести этапов: приём запросов, характеристика пользователя, анализ запроса, поиск информации, предоставление ответа, анализ изучения эффективности обслуживания [16].

Е. Д. Жабко считает, что «технология справки при онлайновом обслуживании включает в себя разовый запрос пользователя (без определения степени свёртывания предоставляемой информации) + библиографический/полнотекстовый поиск информации + ответ пользователю» [12. С. 7]. В таком изложении действительно представлены основные элементы СБО, но не его этапы, за исключением «поиска информации». Этапы СБО должны определяться как последовательность действий библиографа.

Уточнённый и обобщённый алгоритм СБО состоит из шести этапов: приём запроса, формирование поискового образа запроса (ПОЗ), определение источников поиска, поиск информации, оформление ответа, выдача (от- 
правление) ответа (см. Приложение).

В определении СБО нецелесообразно говорить о характере информационных запросов и выдаваемой информации. Известно, что первоначально к компетенции СБО относили только выполнение библиографических запросов, позднее - библиографических и фактографических. Однако в последние годы в связи с появлением полнотекстовых баз данных и электронных документов, доступных и разрешённых для копирования, многие пользователи библиотек обращаются в справочно-библиографическую службу с запросами на полные тексты документов.

Актуальными для учёных стали библиометрические данные, соответственно в справочно-библиографических службах библиотек появились запросы на библиометричекую информацию. Особую ценность для потребителей информации имеют справки аналитического характера, требующие не только выявления и подбора источников информации, но и их сравнительного анализа и оценки, подготовки аналитических материалов. Вряд ли следует ограничивать возможности и обязанности служб СБО, если они способны удовлетворить возрастающие информационные потребности пользователей.

Среди видов ответов, выдаваемых библиотеками в ходе СБО, чаще всего называют справки и консультации. Некоторые авторы говорят только о справках. Например, Г. Н. Диомидова пишет: «Ответ на разовый запрос принято считать справкой» [9. С. 224]. В учебнике украинских авторов В. А. Бурана, Е. П. Довгополой и В. В. Пупченко сначала утверждается, что «ответы бывают трёх видов: ответ-справка, ответ-консультация, ответотказ», а ниже говорится: «Справки бывают библиографические, фактографические, методико-консультативные» [3. С. 224], т.е. практически любой положительный ответ назван справкой.

В учебнике «Библиографическая работа в библиотеке: организация и методика» [2] в главе, написанной Д. Я. Коготковым, в форме учёта СБО дана графа «Тип справки», где представлены: тематическая, уточняющая, адресно-библиографическая, фактографическая, консультационная справки, и отдельной графой - «Переадресование». В учебнике Д. Я. Коготкова «Библиографическая деятельность библиотеки. Организация, технология, управление» [13] среди справок названа «консультативная».

Ответами в процессе СБО могут быть как справки, так и консультации, а также отказ, который должен содержать обоснование невозможности положительного ответа либо информацию о службе, которая могла бы удовлетворить запрос. Справка в СБО - это ответ на разовый информационный запрос пользователя, содержащий любую запрашиваемую информацию, доступную в документальных источниках (библиографическую или факто- 
графическую, полнотекстовую или аналитическую и т.д.).

Консультация - это советы пользователю о том, как самостоятельно найти нужную информацию (какие использовать источники, методику поиска информации). Кроме того, возможен ответ-переадресование с указанием библиотеки или службы, в которую следует обратиться пользователю. После создания службы электронной доставки документов (ЭДД) при запросах на полный текст документа, отсутствующий в базах данных, рекомендуется давать соответствующую ссылку на службу ЭДД.

Решение о том, какой ответ дать пользователю, библиограф принимает в процессе или в результате поиска информации. Не всегда вид ответа соответствует виду поступившего запроса. Иногда на один запрос приходится выполнить несколько разных справок (например, на библиографический адресный запрос - сначала уточняющую справку, затем адресную, а при отсутствии требуемого документа рекомендовать список документов по теме запроса) или предложить читателю и справку, и консультацию (как вести поиск информации по теме). В любом случае в ответе должны быть библиографические сведения о найденых документах и просмотреных источниках информации, поскольку речь идёт о библиографическом обслуживании.

В первом стандарте на библиографическую терминологию соответствующее направление деятельности библиотеки было названо справочнобиблиографической работой (СБР): «Библиографическое обслуживание читателей в соответствии с поступившими запросами» [4. С. 3]. После пересмотра стандарта в 1977 г. термин СБР был заменён на СБО, причём определение его не изменилось [5. С. 5]. Следовательно, СБР можно считать устаревшим или нерекомендуемым синонимом СБО.

В. А. Фокеев в терминологическом словаре «Библиографическая наука и практика» даёт определение СБР, по сути аналогичное СБО: «Доведение информации о документах и/или фактических сведений, заключённых в документах, до потребителей в соответствии с запросами в форме выполненных библиографических, адресных, уточняющих, тематических, фактографических справок, совокупность процессов составления и выдачи пользователям библиографических справок» [20. С. 224]. В целом его можно принять, но с уточнением характера запросов (разовых) и без перечисления видов справок (причём, после слова «библиографических» не должно быть запятой), а также с уточнением количества и названий процессов, составляющих СБО.

Определяя СБО, В. А. Фокеев пишет: «Вид справочно-библиографической работы, связанной с подготовкой, выполнением и доведением до читателей фактографических и библиографических справок» [Там же. 
С. 225]. Исходя из последнего определения, можно предположить, что к СБР относится ещё какой-то вид деятельности кроме СБО, что не соответствует определению СБР. Скорее всего, СБР следует считать синонимом СБО или характеризовать следующим образом: работа библиотеки (или другого информационного посредника) по удовлетворению разовых информационных запросов потребителей информации.

Украинская исследовательница Т. В. Добко вводит новый термин и понятие справочно-библиографическая деятельность (СБД), трактуемое как «отрасль научно-информационной деятельности, направленная на создание справочно-библиографических информационных продуктов и предоставление библиографических услуг внутренним и внешним пользователям библиотеки в соответствии с их эксклюзивными запросами или в опережающем режиме путём формирования научно-поискового аппарата, осуществления навигации, организации доступа к информационным ресурсам» [10. С. 55]. Очерченный объём понятия СБД даёт возможность рассматривать СБО в комплексе с другими направлениями информационной деятельности библиотеки, расширяя поле научного анализа.

И. Г. Моргенштерн ввёл понятие справочно-библиографическая служба $(C Б C)$, обозначающее «систему элементов библиотеки, обеспечивающих функционирование СБО», к которым относятся: справочно-библиографический аппарат (СБА), библиографы (библиотекари) - субъекты СБО, материально-техническая база, организационные формы обслуживания [15. С. 13].

Можно ли говорить о видах СБО? И. Г. Моргенштерн отмечал: СБО осуществляется в двух режимах - оперативном и продлённом, и так характеризовал соответствующие виды СБО: «Оперативное СБО осуществляется тотчас после поступления запроса, обычно при непосредственном контакте с пользователем (а также по телефону), синхронно. Продлённое СБО осуществляется диахронно при невозможности оперативно найти релевантный ответ и согласии пользователя на ожидание его» [Там же].

В связи с широким распространением компьютеризации и информационно-коммуникационных технологий, можно выделить виды СБО в зависимости от применяемых средств поиска информации: традициионое (нонэлектронное) и электронное. Терминоэлемент нонэлектронный, предложенный Ю. Н. Столяровым [19], обозначает источники, не являющиеся электронными. Для многих библиотек, не имеющих электронных источников информации, нонэлектронное СБО остаётся актуальным. СБО, сочетающее электронные и неэлектронные источники поиска ответов на запросы, можно назвать комплексным.

Электронное СБО может быть стационарным (предоставляющим 
услуги в стенах библиотеки) или виртуальнымм (онлайновым). Виртуальное СБО, или виртуальное справочное обслуживание (ВСО) - это СБО пользователей библиотеки, организованное через интернет, когда пользователи имеют возможность обратиться в библиотеку с информационным запросом с помощью сети и через неё получить ответ.

На несоответствие значения слова «виртуальный» и содержания, вкладываемого в понятие «виртуальная библиотека», обратил внимание Ю. Н. Столяров: он заметил, что «виртуальный» в переводе с латыни означает «возможный, несуществующий, иллюзионный» [18]. По его мнению, «виртуальная реальность» в принципе невозможна: как только она становится реальностью, она перестает быть виртуальной. Однако термины с прилагательным «виртуальный» нашли своих сторонников.

Виртуальная реальность трактуется сейчас как искусственное пространство, созданное компьютерами и имеющее все признаки реальности. Терминоэлемент виртуальный получил новое значение и в настоящее время активно используется как при характеристике виртуального информационного пространства, так и библиографического обслуживания через интернет.

СБО и ВСО нельзя рассматривать как разные виды библиографического обслуживания, поскольку второе - разновидность первого. Виртуальное СБО осуществляют виртуальные справочные службы (ВCC), которые выполняют «виртуальные справки». ВСС - это подразделение библиотеки, организующее СБО отдалённых пользователей с помощью информационнокоммуникационных технологий.

Проанализировав названия современных справочных служб, Т. В. Добко предложила применять термин электронная справочная служба или онлайновые справочные услуги [10]. Однако электронная справочная служба может работать и без выхода в интернет, а онлайновая связь означает непосредственную, прямую связь между коммуникаторами, «которая находится в состоянии подключения», в режиме реального времени, без какой-либо отсрочки.

Приём запроса у отдалённого пользователя и выдача справки далеко не всегда происходят в режиме онлайн; по большей части они разведены во времени. В то же время терминоэлемент онлайновый получил новое значение: организованный через интернет, путём подключения к интернету. В таком значении «онлайновый» и «виртуальный» совпадают, и любое «виртуальное СБО» можно также назвать онлайновым.

Основное значение понятия виртуальная справка - ответ на разовый информационный запрос отдалённого пользователя, который осуществляется с помощью информационно-коммуникационных технологий. Иногда подчёркивают интерактивный режим, в котором выполняются справки, однако он подразумевает непосредственное общение библиотекаря с пользо- 
вателем, а такое общение не всегда удаётся организовать через интернет.

Виртуальной справкой называют также службу СБО отдалённых пользователей, организованную с помощью информационно-коммуникативных технологий через интернет. В частности, государственный стандарт Украины ДСТУ 7448:2013 «Информация и документация. Библиотечноинформационная деятельность. Термины и определения понятий» характеризует «виртуальную справку» так: «Библиотечная служба, которая предоставляет справки на разовый информационный запрос виртуального пользователя библиотеки, содержащие фактографическую и/или библиографическую информацию, а также ссылку на Интернет-ресурсы, или может составить перечень источников информации по конкретной теме» [11. С. 29].

Такое определение слишком многословное и непрофессиональное, библиографическая информация - это и есть «перечень источников информации», в том числе и ресурсов интернета. Стандартизация термина виртуальная справка в значении справочной службы создаёт нежелательную конкуренцию между понятиями справка и справочная служба.

Информационные продукты и услуги, предоставляемые библиотеками на современном этапе в процессе СБО, можно представить в многоаспектной фасетной классификации (табл.).

Таблица

\begin{tabular}{|c|c|c|}
\hline $\begin{array}{c}\text { Признак } \\
\text { классификации } \\
\end{array}$ & Справки & Консультации \\
\hline $\begin{array}{l}\text { 1. По месту } \\
\text { предоставления }\end{array}$ & $\begin{array}{l}\text { 1. Стационарные (внутренние). } \\
\text { 2. Внешние. }\end{array}$ & $\begin{array}{l}\text { 1. Стационарные (внутренние). } \\
\text { 2. Внешние. }\end{array}$ \\
\hline $\begin{array}{l}\text { 2. По форме } \\
\text { выдачи }\end{array}$ & $\begin{array}{l}\text { 1. Устные. } \\
\text { 2. Письменные. } \\
\text { 3. Телефонные. } \\
\text { 4. Электронные: } \\
\text { на электронную почту, } \\
\text { на виртуальную форму, } \\
\text { в чате. }\end{array}$ & $\begin{array}{l}\text { 1. Устные. } \\
\text { 2. Письменные. } \\
\text { 3. Электронные: } \\
\text { на электронную почту, } \\
\text { на виртуальную форму, } \\
\text { в чате. }\end{array}$ \\
\hline $\begin{array}{l}\text { 3. По виду и } \\
\text { содержанию } \\
\text { информации }\end{array}$ & $\begin{array}{l}\text { 1. Библиографические: } \\
\text { адресные, } \\
\text { тематические, } \\
\text { уточняющие. } \\
\text { 2. Фактографические. } \\
\text { 3. Полнотекстовые } \\
\text { 4. Библиометрические. } \\
\text { 5. Библиотечно-ориентировочные. } \\
\text { 6. Аналитические. }\end{array}$ & $\begin{array}{l}\text { 1. Библиографические. } \\
\text { 2. Фактографические. } \\
\text { 3. Библиометрические. } \\
\text { 4. Библиотечно-ориентировочные. } \\
\text { 5. Учебные. }\end{array}$ \\
\hline
\end{tabular}


Продолжение таблицы

\begin{tabular}{|l|l|l|}
\hline \multicolumn{1}{|c|}{$\begin{array}{c}\text { Признак } \\
\text { классификации }\end{array}$} & \multicolumn{1}{|c|}{ Справки } & \multicolumn{1}{|c|}{ Консультации } \\
\hline $\begin{array}{l}\text { п. По видам } \\
\text { предоставляемых } \\
\text { источников } \\
\text { информации }\end{array}$ & $\begin{array}{l}\text { 1. Традиционные } \\
\text { (нонэлектронные). } \\
\text { 2. Интернет-ориентированные } \\
\text { (веблиографические). }\end{array}$ & $\begin{array}{l}\text { 1. Традиционные } \\
\text { (нонэлектронные). } \\
\text { 2. Интернет-ориентированные } \\
\text { (веблиографические). }\end{array}$ \\
\hline $\begin{array}{l}\text { 3. Пазновидовые. } \\
\text { поиска ответа }\end{array}$ & 1. Электронные: & 1. Электронные: \\
& электронный каталог, & электронный каталог, \\
& базы данных, & базы данных, \\
& интернет-ресурсы. & интернет-ресурсы. \\
& 2. Нонэлектронные: & 2. Нонэлектронные: \\
& карточные каталоги, & карточные каталоги, \\
& картотеки, & картотеки, \\
& печатные издания. & печные издания. \\
& З. Комплексные. &
\end{tabular}

Прокомментируем некоторые термины.

Справки и консультации - это основные виды ответов, выдаваемых пользователям в процессе СБО. Анализ показывает, что виды справок и консультаций во многих случаях совпадают, однако есть и некоторые отличия.

По месту предоставления справки и консультации делятся на стационарные (внутренние) и внешние. Стационарные предоставляются в помещении библиотеки, в присутствии пользователя. Внешние - отдалённому пользователю через телефонную связь, традиционную или электронную почту, чат или специальную веб-форму, расположенную на веб-сайте библиотеки.

В последнее время наиболее популярным является СБО через специальные веб-формы, получившие название «Виртуальная справка» или «Виртуальная справочная служба». Поэтому внешние справки получают наименование виртуальные. Они не всегда выполняются в режиме онлайн, т.е. без перерыва между получением запроса и предоставлением ответа. Общее название «электронная справка» или «цифровая справка» для внешних справок не подходит, потому что последние могут быть неэлектронными.

Среди видов справок и консультаций по форме выдачи выделяются электронные - выполняемые средствами электронных (цифровых) технологий. Они выдаются в стенах библиотеки или направляются пользователю по каналу связи.

По виду и содержанию информации, предоставляемой пользователю, уместно, кроме традиционных библиографических и фактографических спра- 
вок и консультаций, выделить библиотечно-ориентировочные, т.е. содержащие информацию о информационных ресурсах библиотеки, условиях доступа к ним, режиме работы библиотеки. Кроме того, всё более востребованы полнотекстовые справки, содержащие полный текст документа (если такая услуга отвечает действующему законодательству и правилам библиотеки).

Среди пользователей университетских библиотек, преимущественно профессорско-преподавательского состава, возросли потребности в получении библиометрических справок и консультаций. Перспективный вид справок - аналитические, предусматривающие анализ документов, о которых предоставляется информация, на предмет их соответствия не только запросу, но и информационной потребности пользователя.

Особый вид консультаций - учебные, осуществляемые не только в традиционной устной форме, но и в виде специальных программ, выставленных на сайте библиотеки.

По видам предоставленных источников информации выделим интернет-ориентированные (веблиографические) справки и консультации, так как некоторые пользователи испытывают потребность в информации о сетевых ресурсах.

По источникам поиска ответа отметим электронные справки и консультации, для подготовки которых используют электронные источники, как внутренние библиотечные, так и внешние, сетевые. Электронные источники поиска информации - электронный каталог, отображающий состав определённого фонда документов, и базы данных, не связанные с фондом. В нонэлектронных справках и консультациях для поиска информации используют традиционные бумажные (печатные и рукописные) карточные и книжные ресурсы. Комплексные справки и консультации создаются как по традиционным, так и по электронным источникам.

Перечисленные виды справок и консультаций выделены методом параллельной фасетной классификации. Они независимы друг от друга, за исключением некоторых фасетов, где применена иерархическая классификация (в частности, библиографических справок и консультаций: адресные, тематические и уточняющие). Понятие «типы» как определённый уровень классификации здесь не используется.

Определить типы справок и консультаций можно, если применить для их характеристики одновременно несколько признаков. Например: письменная библиографическая тематическая справка; электронная библиографическая адресная справка; внешняя электронная учебная консультация и т.п.

Рассмотрение базовых терминов по теме исследования показало, что становлению профессиональной терминологии СБО уделялось значитель- 
ное внимание. Вместе с тем некоторые решения относительно самих терминов или их определения остаются дискуссионными и нуждаются в обсуждении, а также в дальнейшем отражении в терминологических справочниках и стандартах.

\section{СПИСок источников}

1. Абросимова Н. В. Библиографическая деятельность библиотеки : учеб.-практ. пособие / Н. В. Абросимова. - Санкт-Петербург : Профессия, 2013. - 159 с. - (Азбука библиотечной профессии).

Abrosimova N.V. Bibliograficheskaja dejatel'nost' biblioteki : ucheb.-prakt. posobie / N.V. Abrosimova. - SPb. : Professija, 2013. - 159 s. - (Azbuka bibliotechnoj professii).

2. Библиографическая работа в библиотеке : организация и методика / под ред. О. П. Коршунова. - Москва : Кн. палата, 1990. - 255 с. - Из содерж.: Гл. 10. Организация и методика справочно-библиографического обслуживания / Н. Н. Щерба; Гл. 14. Управление библиографичекой деятельностью библиотеки / Д. Я. Коготков.

Bibliograficheskaja rabota $v$ biblioteke : organizacija i metodika / pod red. O. P. Korshunova. M. : Kn. palata, 1990. - 255 s. - Iz soderzh.: Gl. 10. Organizacija i metodika spravochnobibliograficheskogo obsluzhivanija / N. N. Shherba; Gl. 14. Upravlenie bibliografichekoj dejatel'nost'ju biblioteki /D. Ja. Kogotkov.

3. Буран В. Я. Бібліографія. Загальний курс : навч. посіб. для учнів культ.-освіт. училищ / В. Я. Буран, О. П. Довгопола, В. В. Пупченко ; за ред. В. Я. Бурана. - К. : Вища шк., 1984. $216 \mathrm{c}$.

Buran V. Ya. Bibliohrafiia. Zahal'nyj kurs : navch. posib. dlia uchniv kul't.-osvit. uchylysch / V. Ya. Buran, O. P. Dovhopola, V. V. Pupchenko ; za red. V. Ya. Burana. - K. : Vyscha shk., 1984. $216 \mathrm{~s}$.

4. ГОСТ 16448-70. Библиография : термины и определения : [Введ. 01.07.1971]. - Изд. офиц. - Москва : Гос. ком. стандартов Совета Министров СССР, 1970. - 12 с.

GOST 16448-70. Bibliografija : terminy i opredelenija : [Vved. 01.07.1971]. - Izd. ofic. - M. : Gos. kom. standartov Soveta Ministrov SSSR, 1970. - 12 s.

5. ГОСТ 7.0-77. Библиография. Термины и определения. - Введ. 1977-07-01. - Москва : Изд-во стандартов, 1977. - 24 с.

GOST 7.0-77. Bibliografija. Terminy i opredelenija. - Vved. 1977-07-01. - M. : Izd-vo standartov, 1977. $-24 \mathrm{~s}$.

6. ГОСТ 7.0-84. Библиографическая деятельность. Основные термины и определения // Стандарты по библ. делу и библиогр. - Москва : Изд-во стандартов, 1985. - С. 5-28.

GOST 7.0-84. Bibliograficheskaja dejatel'nost'. Osnovnye terminy i opredelenija // Standarty po bibliotechnomu delu i bibliografii. - M. : Izd-vo standartov, 1985. - S. 5-28.

7. ГОСТ 7.0-99. Информационно-библиотечная деятельность, библиография. Термины и определения : межгос. стандарт. - Взамен ГОСТ 7.0-84 ; введ. 01.07.2000 // Стандарты по библ.-информ. деятельности. - Санкт-Петербург : Профессия, 2003. - С. 11-38. 
GOST 7.0-99. Informacionno-bibliotechnaja dejatel'nost', bibliografija. Terminy i opredelenija : mezhgos. standart. - Vzamen GOST 7.0-84 ; vved. 01.07.2000 // Standarty po bibliotechnoinformacionnoj dejatel'nosti. - SPb. : Professija, 2003. - S. 11-38.

8. Губанова Г. А. Терминосистема библиографии : современное состояние / Г. А. Губанова, И. Г. Моргенштерн // Библиогр. - 2002. - № 1. - С. 13-16.

Gubanova G. A. Terminosistema bibliografii : sovremennoe sostojanie / G. A. Gubanova, I. G. Morgenshtern // Bibliografija. - 2002. - № 1. - S. 13-16.

9. Диомидова Г.Н. Библиографоведение : учеб. для сред. проф. учеб. заведений / Г. Н. Диомидова. - Санкт-Петербург : Профессия, 2002. - 287 с. - (Библиотека).

Diomidova G. N. Bibliografovedenie : ucheb. dlja sred. profession. ucheb. zavedenij / G. N. Diomidova. - SPb. : Professija, 2002. - 287 s. - (Biblioteka).

10. Добко Т. В. Довідково-бібліографічна діяльність наукових бібліотек Національної академії наук України : становлення та розвиток (XX ст. - перше десятиліття XXI ст.) / Т. В. Добко ; відп. ред. О.С. Онищенко ; НАН України, Нац. б-ка України ім. В. І. Вернадського. - К. : НБУВ, 2013. - 374 с.

Dobko T. V. Dovidkovo-bibliohrafichna diial'nist' naukovykh bibliotek Natsional'noi akademii nauk Ukrainy : stanovlennia ta rozvytok (KhKh st. - pershe desiatylittia KhKhI st.) / T. V. Dobko ; vidp. red. O. S. Onyschenko ; NAN Ukrainy, Nats. b-ka Ukrainy im. V. I. Vernads'koho. - K. : NBUV, 2013. - 374 s.

11. ДСТУ 7448:2013. Інформація та документація. Бібліотечно-інформаційна діяльність. Терміни та визначення понять. - Прийнято та надано чинності наказом Мінекономрозвитку України від 29.11.2013 № 1423. - Вид. офіц. - К. : Мінекономрозвитку України, 2014. III, 41 с. - (Національний стандарт України).

DSTU 7448:2013. Informatsiia ta dokumentatsiia. Bibliotechno-informatsijna diial'nist'. Terminy ta vyznachennia poniat'. - Pryjniato ta nadano chynnosti nakazom Minekonomrozvytku Ukrainy vid 29.11.2013 № 1423. - Vyd. ofits. - K. : Minekonomrozvytku Ukrainy, 2014. - III, 41 s. (Natsional'nyj standart Ukrainy). C. 3-11.

12. Жабко Е. Д. Онлайновое СБО: особенности развития // Библиогр. - 2005. - № 3. -

Zhabko E. D. Onlajnovoe SBO: osobennosti razvitija // Bibliogr. - 2005. - № 3. - S. 3-11.

13. Коготков Д. Я. Библиографическая деятельность библиотеки. Организация, технология, управление : учеб. / Д. Я. Коготков. - Санкт-Петербург : Профессия, 2005. - 304 с.

Kogotkov D. Ja. Bibliograficheskaja dejatel'nost' biblioteki. Organizacija, tehnologija, upravlenie : uchebnik / D. Ja. Kogotkov. - SPb. : Professija, 2005. - 304 s.

14. Коршунов О. П. Библиографоведение. Общий курс : учеб. для библ. фак. ин-тов культуры, ун-тов и пед. вузов / О. П. Коршунов. - Москва : Кн. палата, 1990. - 232 с.

Korshunov O. P. Bibliografovedenie. Obshij kurs : ucheb. dlja bibl. fak. in-tov kul'tury, untov i ped. vuzov / O. P. Korshunov. - M. : Kn. palata, 1990. - 232 s.

15. Моргенштерн И. Г. Справочно-библиографическое обслуживание в библиотеках : науч.-практ. пособие / И. Г. Моргенштерн. - Москва : Либерея, 1999. - 79 с.

Morgenshtern I. G. Spravochno-bibliograficheskoe obsluzhivanie v bibliotekah : nauch.-prakt. posobie /I. G. Morgenshtern. - M. : Libereja, 1999. - 79 s. 
16. Разумова Э. Г. Технологические аспекты реализации онлайнового справочнобиблиографического обслуживания удаленных пользователей (на примере Виртуальной справочной службы РНБ «Спроси библиографа») [Электрон. ресурс] // Виртуал. справоч. служба Рос. нац. б-ки. - Режим доступа: http://www. vss.nlr.ru.

Razumova Je.G. Tehnologicheskie aspekty realizacii onlajnovogo spravochnobibliograficheskogo obsluzhivanija udalennyh pol'zovatelej (na primere Virtual'noj spravochnoj sluzhby RNB «Sprosi bibliografa») [Jelektronnyj resurs] // Virtual'naja spravochnaja sluzhba Rossijskoj nacional'noj biblioteki.

17. Справочно-библиографическое обслуживание / Моргенштерн И. Г. // Справ. библиографа. - Санкт-Петербург : Профессия, 2002. - С. 444-462.

Spravochno-bibliograficheskoe obsluzhivanie / Morgenshtern I. G. // Spravochnik bibliografa. SPb. : Professija, 2002. - S. 444-462.

18. Столяров Ю. Н. Критика термина «виртуальная библиотека» / Ю. Н. Столяров // Науч. и техн. б-ки. - 1997. - № 8. - С. 15-20.

Stoljarov Ju. N. Kritika termina «virtual'naja biblioteka» / Ju. N. Stoljarov // Nauch. i tehn. b-ki. - 1997. - № 8. - S. 15-20.

19. Столяров Ю. Н. Нонэлектронный документ: правомерность термина // Там же. 2012. - № 9. - C. 38-43.

Stoljarov Ju. N. Nonjelektronnyj dokument: pravomernost' termina // Nauch. i tehn. b-ki. 2012. - № 9. - S. 38-43.

20. Фокеев В. А. Библиографическая наука и практика : терминолог. слов. / В. А. Фокеев. - Санкт-Петербург : Профессия, 2008. - 270 с.

Fokeev V. A. Bibliograficheskaja nauka i praktika : terminol. slov. / V. A. Fokeev. - SPb. : Professija, 2008. -270 s.

Приложение

\section{Алгоритм справочно-библиографического обслуживания}

1. Приём запроса.

1.1. Уточнение сведений о читателе.

1.2. Уточнение сведений о цели запроса.

1.3. Определение темы.

1.3.1. Формулировка темы.

1.3.2. Определение отрасли знания.

1.3.3. Формирование ключевых слов.

1.4. Уточнение объёма нужной информации.

1.4.1. Нужные виды документов.

1.4.2. Хронологические границы отбора документов.

1.4.3. Язык документов.

1.4.4. Приблизительное количество записей. 
2. Формирование поискового образа запроса (ПОЗ).

2.1. Определение предметных рубрик.

2.2. Кодировка запроса по схеме классификации (индексирование).

3. Определение источников поиска.

3.1. Электронные каталог и картотека данной библиотеки.

3.2. Другие электронные БД данной библиотеки.

3.3. Карточные каталоги и СКС данной библиотеки.

3.4. Другие картотеки библиотеки.

3.5. Справочные издания.

3.6. Печатные БП.

3.7. Интернет-ресурсы.

4. Поиск информации по определённым источникам в соответствии с объёмом нужной информации и ПОЗ.

5. Оформление ответа.

5.1. Описание документов.

5.2. Указание шифра (местонахождения) каждого документа.

5.3. Формирование библиографического списка.

5.4. Указание использованных источников поиска.

5.5. Написание письма-ответа.

6. Выдача (отправление) ответа.

Galina Shvetsova-Vodka, Dr. Sci. (History), Professor, Professor of Library Studies and Bibliography, Rovno State University of the Humanities; Rovno, Ukraine;

shvetsova43@yandex.ru

12 S. Bandera str., Rovno, 33028 Ukraine

Zoya Romanukha, Cand. Sci. (Social Communications), leading methodologist, Rovno Regional Universal Scientific Library, Rovno, Ukraine;

romanuhazoya@meta.ua

6 Korolenka Square, Rovno, 33028 Ukraine 